\title{
Hemodynamic Predictors of Mortality in Adults with Sickle Cell Disease
}

\author{
Alem Mehari ${ }^{1,2 *}$, Shoaib Alam ${ }^{1 *}$, Xin Tian ${ }^{3}$, Michael J. Cuttica ${ }^{4}$, Christopher F. Barnett ${ }^{5}$, \\ George Miles6, Dihua $\mathrm{Xu}^{3}$, Catherine Seamon7, Patricia Adams-Graves ${ }^{8}$, Oswaldo L. Castro ${ }^{1,2}$, \\ Caterina P. Minniti7, Vandana Sachdev¹, James G. Taylor VI7, Gregory J. Kato7t, \\ and Roberto F. Machado9†
}

\begin{abstract}
${ }^{1}$ Cardiovascular and Pulmonary Branch, National Heart, Lung, and Blood Institute, Bethesda, Maryland; ${ }^{2}$ Howard University College of Medicine, Washington, DC; ${ }^{3}$ Office of Biostatistics Research, National Heart, Lung, and Blood Institute, Bethesda, Maryland; ${ }^{4}$ Pulmonary and Critical Care Medicine, Northwestern University Feinberg School of Medicine, Chicago, Illinois; ${ }^{5}$ Division of Cardiology, University of California San Francisco, San Francisco, California; ${ }^{6}$ Laboratory of Pathology, National Cancer Institute, Bethesda, Maryland; ${ }^{7}$ Hematology Branch, National Heart, Lung, and Blood Institute, Bethesda, Maryland; ${ }^{8}$ University of Tennessee Health Science Center, Memphis, Tennessee; and ${ }^{9}$ Section of Pulmonary, Critical Care Medicine, Sleep and Allergy, University of Illinois, Chicago, Illinois
\end{abstract}

\begin{abstract}
Background: Pulmonary hypertension (PH) in adults with sickle cell disease (SCD) is associated with early mortality, but no prior studies have evaluated quantitative relationships of mortality to physiological measures of pre- and postcapillary $\mathrm{PH}$.

Objectives: To identify risk factors associated with mortality and to estimate the expected survival in a cohort of patients with SCD with $\mathrm{PH}$ documented by right heart catheterization.

Methods: Nine-year follow-up data (median, $4.7 \mathrm{yr}$ ) from the $\mathrm{Na}$ tional Institutes of Health SCD PH screening study are reported. A total of 529 adults with SCD were screened by echocardiography between 2001 and 2010 with no exclusion criteria. Hemodynamic data were collected from 84 patients. PH was defined as mean pulmonary artery pressure (PAP) $\geqslant 25 \mathrm{~mm} \mathrm{Hg}$. Survival rates were estimated by the Kaplan-Meier method, and mortality risk factors were analyzed by the Cox proportional hazards regression.

Measurements and Main Results: Specific hemodynamic variables were independently related to mortality: mean PAP (hazard ratio $[\mathrm{HR}], 1.61 ; 95 \%$ confidence interval $[\mathrm{Cl}], 1.05-2.45$ per $10 \mathrm{~mm} \mathrm{Hg}$ increase; $P=0.027)$, diastolic PAP $(\mathrm{HR}, 1.83 ; 95 \% \mathrm{Cl}, 1.09-3.08$ per $10 \mathrm{~mm} \mathrm{Hg}$ increase; $P=0.022$ ), diastolic PAP - pulmonary capillary wedge pressure (HR, $2.19 ; 95 \% \mathrm{Cl}, 1.23-3.89$ per $10 \mathrm{~mm}$ Hg increase; $P=0.008)$, transpulmonary gradient $(\mathrm{HR}, 1.78 ; 95 \% \mathrm{Cl}, 1.14$ 2.79 per $10 \mathrm{~mm} \mathrm{Hg}$ increase; $P=0.011$ ), and pulmonary vascular resistance (HR, $1.44 ; 95 \% \mathrm{Cl}, 1.09-1.89$ per Wood unit increase; $P=0.009)$ as risk factors for mortality.
\end{abstract}

\footnotetext{
(Received in original form July 16, 2012; accepted in final form January 18, 2013)

* These authors contributed equally to this work.

† These senior authors contributed equally to this work.
}

This research was supported by the Division of Intramural Research of the $\mathrm{Na}$ tional Heart, Blood and Lung Institute of the National Institutes of Health (grants 1ZIAHL006011, 1ZIAHL006015, and 1ZIAHL006012) and by National Institutes of Health grant K23HL098454 (R.F.M.).

Author Contributions: Obtaining funding: G.J.K., R.F.M., and J.G.T. Study design: G.J.K., R.F.M., J.G.T., and O.L.C. Patient enrollment: A.M., S.A., C.S., P.A.-G. O.L.C., C.P.M., J.G.T., G.J.K., and R.F.M. Data collection: A.M., S.A., M.J.C., C.F.B., G.M., C.S., C.P.M., V.S., J.G.T., G.J.K., and R.F.M. Data analysis: X.T. and D.X Manuscript drafting: A.M., S.A., G.J.K., and R.F.M. Critically revising the manuscript for important intellectual content: X.T., M.J.C., C.F.B., G.M., D.X., C.S., P.A.-G., O.L.C., C.P.M., V.S., and J.G.T.

Correspondence and requests for reprints should be addressed to Gregory J. Kato, M.D., Hematology Branch, NHLBI, National Institutes of Health, 9000 Rockville Pike, Bethesda, MD. E-mail: gkato@mail.nih.gov

This article has an online supplement, which is accessible from this issue's table of contents at www.atsjournals.org

Am J Respir Crit Care Med Vol 187, Iss. 8, pp 840-847, Apr 15, 2013

Published 2013 by the American Thoracic Society

Originally Published in Press as DOI: 10.1164/rccm.201207-12220C on January 24, 2013 Internet address: www.atsjournals.org

\section{AT A GLANCE COMMENTARY}

Scientific Knowledge on the Subject

It is a matter of scientific controversy whether precapillary pulmonary hypertension (PH) in adults with sickle cell disease (SCD) leads to mortality and whether its characteristics are different from $\mathrm{PH}$ in other patients.

\section{What This Study Adds to the Field}

Our results indicate that mortality in catheterized adults with SCD is proportional to several gold-standard hemodynamic measurements of precapillary $\mathrm{PH}$ severity. This epidemiological evidence implies that precapillary $\mathrm{PH}$ promotes early mortality in this patient population.

Conclusions: Mortality in adults with SCD and $\mathrm{PH}$ is proportional to the physiological severity of precapillary $\mathrm{PH}$, demonstrating its prognostic and clinical relevance despite anemia-induced high cardiac output and less severely elevated pulmonary vascular resistance.

Keywords: sickle cell; pulmonary hypertension; mortality; autopsy

Pulmonary hypertension $(\mathrm{PH})$ is defined as a mean pulmonary artery pressure (mPAP) $\geqslant 25 \mathrm{~mm} \mathrm{Hg}(1)$. Prospective $(2-4)$ and retrospective studies $(5,6)$, most using Doppler echocardiography to estimate systolic pulmonary artery pressure (sPAP), report that 20 to $30 \%$ of adults with sickle cell disease (SCD) have higher than normal sPAP. Our group and others recently reported a $\mathrm{PH}$ prevalence of 6 to $11 \%$ in adults with, which is associated with increased hazard of death $(7,8)$. The hemodynamic characteristics of $\mathrm{PH}$ in adults with SCD are heterogeneous. PH may be precapillary (pulmonary arterial hypertension) or postcapillary (pulmonary venous hypertension) and may be passive or reactive in nature (9-14), emphasizing the need for right heart catheterization (RHC) to confirm the diagnosis of $\mathrm{PH}$ and for accurate hemodynamic stratification to determine treatment and follow-up.

Pulmonary vascular lesions characteristic of precapillary $\mathrm{PH}$, including plexiform lesions, have been described in one third to two thirds of patients with SCD in autopsy studies (15-18). Precapillary $\mathrm{PH}$ is characterized by a progressive elevation in pulmonary artery pressure and pulmonary vascular resistance, leading to right ventricular failure and death (19). Despite only modest elevation of estimated SPAP, patients with SCD and 
estimated sPAP 2 SD above the normal mean have 10-fold higher risk for early mortality compared with patients with SCD without this echocardiographic abnormality (2-4, 20). However, these noninvasive data have provoked controversy (21-23), with some researchers expressing skepticism that $\mathrm{PH}$ in SCD is clinically significant (24). Few SCD studies have presented confirmatory physiologic measurements with RHC, the standard for $\mathrm{PH}$ diagnosis $(4,8-10,25)$, and no prospective studies have adequately examined hemodynamic predictors of mortality other than the single threshold value of mPAP to diagnose $\mathrm{PH}$.

Data from idiopathic pulmonary arterial hypertension studies identify baseline hemodynamic variables as an important predictor of survival (26-28). Other studies of idiopathic pulmonary arterial hypertension and precapillary $\mathrm{PH}$ associated with other disorders have shown clinical variables, such as poor exercise capacity as measured by the 6-minute walk distance (6MWD) test and advanced World Health Organization functional class (WHO FC), and certain biomarkers are predictors of a poor prognosis $(29,30)$. However, Simonneau and Parent have critically questioned the clinical relevance of PH in SCD (24), in part because of the atypically high cardiac output that is an adaptive response to severe anemia and the very low oxygen-carrying capacity in these patients and the pulmonary vascular resistance that, due to adaptation to high flow, is not as highly elevated. We recently reported the prevalence and prognostic significance of $\mathrm{PH}$ in a large cohort of adults with SCD (7), but all published analyses have only evaluated a threshold effect of mean pulmonary artery pressure that satisfies consensus diagnostic criteria. We hypothesize that that severity of $\mathrm{PH}$, especially precapillary $\mathrm{PH}$, is proportional to mortality in SCD. Our new analysis in this study demonstrates the quantitative relationship of well accepted right heart catheterization-defined precapillary $\mathrm{PH}$ variables to death in adults with SCD. Some of the results of these studies have been previously reported in the form of an abstract (31).

\section{METHODS}

This registry study was approved by the Institutional Review Board at the National Institutes of Health. All subjects provided written informed consent to studies in which clinical, laboratory, echocardiographic, and/or RHC data were obtained (ClinicalTrials.gov identifiers NCT00011648, NCT00081523, NCT00023296, and NCT00352430). Subjects who underwent RHC between March 13, 2002 and June 8, 2010 were included. The diagnosis of SCD was confirmed by HPLC of hemoglobin. The selection process is summarized in Figure 1. The cohort was assembled from 529 subjects with SCD enrolled and screened at the National Institutes of Health or at Howard University Hospital, of whom approximately 2\% were referred with suspected or proven pulmonary hypertension. Out of the 529 subjects with SCD, 84 underwent RHC based on elevated tricuspid regurgitant velocity (TRV) on echocardiography and clinical suspicion of $\mathrm{PH}$ defined as TRV $\geqslant 2.8 \mathrm{~m} / \mathrm{s}$ accompanied by $6 \mathrm{MWD}<500 \mathrm{~m}$ or unexplained dyspnea or oxygen desaturation. RHC was performed in $33 \%$ of subjects with TRV $\geqslant 2.5 \mathrm{~m} / \mathrm{s}, 52 \%$ of subjects with TRV $\geqslant 2.8 \mathrm{~m} / \mathrm{s}$, and $66 \%$ of those with TRV $\geqslant 3 \mathrm{~m} / \mathrm{s}$. The $\mathrm{PH}$ group was categorized hemodynamically to have postcapillary $\mathrm{PH}$ if $\mathrm{mPAP}$ was $\geqslant 25 \mathrm{~mm} \mathrm{Hg}$ and pulmonary capillary wedge pressure (PCWP) was $>15 \mathrm{~mm} \mathrm{Hg}$, and precapillary $\mathrm{PH}$ if $\mathrm{mPAP} \geqslant 25 \mathrm{~mm} \mathrm{Hg}, \mathrm{PCWP} \leqslant 15 \mathrm{~mm} \mathrm{Hg}$ (32). These results were presented in part at the annual meeting of the American Society of Hematology (31). Additional details are provided in the online supplement.

\section{RESULTS}

\section{Study Population}

Baseline characteristics of subjects who underwent RHC ( $\mathrm{n}=$ $84)$ and the noncatheterized subjects with SCD $(n=445)$ are shown in Table E1 in the online supplement. Most study

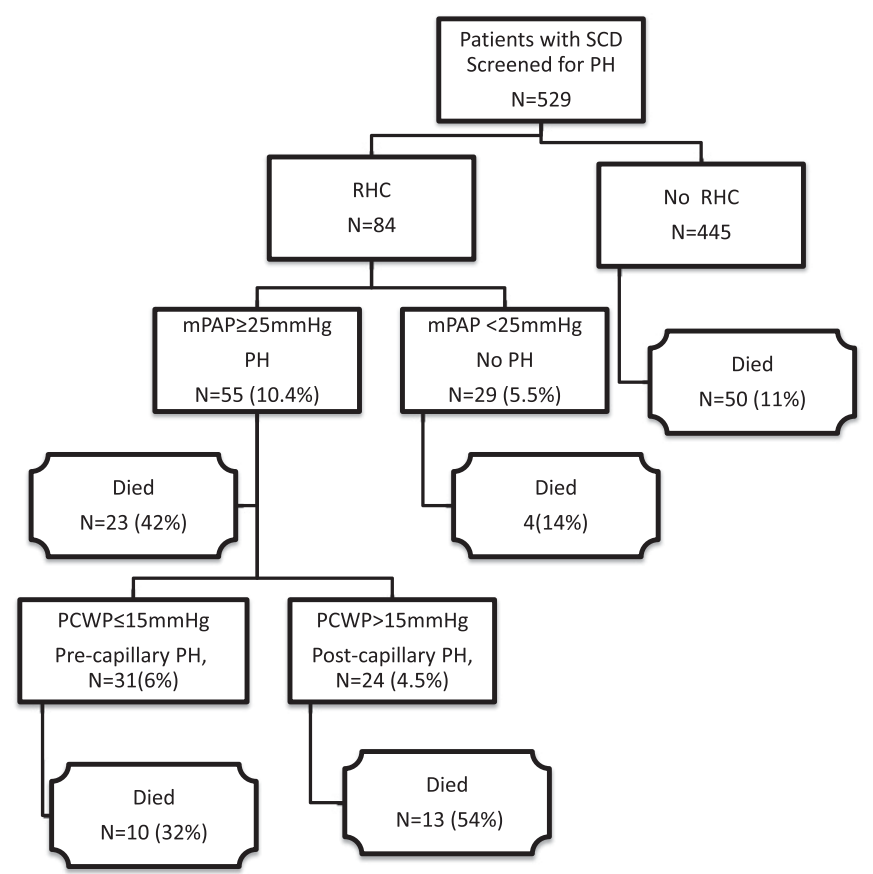

Figure 1. Schematic diagram of study population. mPAP $=$ mean pulmonary artery pressure; PCWP = pulmonary capillary wedge pressure; $\mathrm{PH}=$ pulmonary hypertension; precapillary $\mathrm{PH}=$ pulmonary arterial hypertension; postcapillary $\mathrm{PH}=$ pulmonary venous hypertension; $\mathrm{RHC}=$ right heart catheterization; $\mathrm{SCD}=$ sickle cell disease.

participants were of African descent (98\%), and the predominant sickle cell phenotype was hemoglobin SS disease $(73 \%)$. Subjects who underwent RHC were older, with mean age of $41 \pm 13$ years compared with $35 \pm 12$ years for those not catheterized $(P<0.001)$. Several laboratory markers were statistically significantly different in SCD and PH compared with the noncatheterized patients with SCD (Table 1). Subjects with SCD and PH demonstrated significantly abnormal cardiopulmonary markers of clinical severity compared with those not catheterized, including higher TRV $(3.2 \pm 0.5$ vs. $2.3 \pm 0.5 \mathrm{~m} / \mathrm{s}$; $P<0.001$ ), higher serum N-terminal prohormone of brain natriuretic peptide (NT-proBNP) level (median, $153 \mathrm{vs.} 58 \mathrm{pg} / \mathrm{ml} ; P<$ 0.001 ), and poor exercise capacity (6MWD $387 \pm 118 \mathrm{~m}$ vs. $486 \pm$ $88 \mathrm{~m} ; P<0.001)$.

Logistic regression analysis showed that TRV and 6MWD are significantly associated with PH diagnosis at RHC. TRV $\geqslant 2.8 \mathrm{~m} / \mathrm{s}$ was highly predictive of PH (compared with subjects with SCD and TRV $<2.8 \mathrm{~m} / \mathrm{s}$; relative risk, $13.05 ; 95 \% \mathrm{CI}, 5.19-32.85 ; P<$ $0.001)$. Compared with the model with TRV alone, the $\mathrm{C}$ statistic (area under the ROC curve) was significantly improved from 0.84 to 0.88 with the addition of $6 \mathrm{MWD}<500 \mathrm{~m}$ in the multivariate model. The clinical relevance of this combined model to predict $\mathrm{PH}$ needs to be validated.

\section{Hemodynamic Parameters}

Fifty-five subjects $(10.4 \%)$ out of the 529 screened SCD population, or 55 out of $84(65.5 \%)$ of those who underwent RHC, were diagnosed with $\mathrm{PH}$ (Figure 1). The $\mathrm{PH}$ group was characterized by mPAP $36 \pm 9 \mathrm{~mm} \mathrm{Hg}$, PVR $227 \pm 149 \mathrm{dyn} \cdot \mathrm{s} \cdot \mathrm{cm}^{-5}, \mathrm{PVRi}$ $417 \pm 264 \mathrm{dyn} \cdot \mathrm{s} \cdot \mathrm{cm}^{-5} \cdot \mathrm{m}^{-2}$, central venous pressure $10 \pm 5 \mathrm{~mm} \mathrm{Hg}$, and high cardiac output $(8.4 \pm 2.5 \mathrm{~L} / \mathrm{min})$ (Table 1$)$. Similarly, the mean mixed venous oxygen saturation $\left(\mathrm{Sv}_{\mathrm{O}_{2}}\right)(69 \pm 8 \%)$ and PVC $(4.5 \pm 3.1 \mathrm{ml} / \mathrm{mm} \mathrm{Hg})$ were mildly depressed in subjects with SCD and PH. A higher percentage of subjects with SCD 
TABLE 1. HEMODYNAMIC AND CLINICAL CHARACTERISTICS OF CATHETERIZED PATIENTS ACCORDING TO PULMONARY HYPERTENSION STATUS

\begin{tabular}{|c|c|c|c|}
\hline Characteristic $(N=84)$ & $\mathrm{PH}(n=55)$ & No $\mathrm{PH}(n=29)$ & $P$ Value \\
\hline $\mathrm{sPAP}, \mathrm{mm} \mathrm{Hg}$ & $58 \pm 15$ & $31 \pm 6$ & $<0.001$ \\
\hline $\mathrm{dPAP}, \mathrm{mm} \mathrm{Hg}$ & $26 \pm 7$ & $13 \pm 4$ & $<0.001$ \\
\hline $\mathrm{PP}, \mathrm{mm} \mathrm{Hg}$ & $32 \pm 12$ & $17 \pm 5$ & $<0.001$ \\
\hline $\mathrm{mPAP}, \mathrm{mm} \mathrm{Hg}$ & $36 \pm 9$ & $19 \pm 4$ & $<0.001$ \\
\hline $\mathrm{CVP}, \mathrm{mm} \mathrm{Hg}(\mathrm{n}=83)$ & $10 \pm 5$ & $6 \pm 3$ & $<0.001$ \\
\hline PCWP, mm Hg & $16 \pm 5$ & $11 \pm 3$ & $<0.001$ \\
\hline TPG, mm Hg & $21 \pm 10$ & $8 \pm 3$ & $<0.001$ \\
\hline dPAP-PCWP, $\mathrm{mm} \mathrm{Hg}$ & $10 \pm 8$ & $2 \pm 3$ & $<0.001$ \\
\hline Cardiac output, L/min & $8.4 \pm 2.5$ & $9.3 \pm 2.3$ & 0.12 \\
\hline Cardiac index, $\mathrm{L} \cdot \mathrm{min}^{-1} \cdot \mathrm{m}^{-2}$ & $4.6 \pm 1.5$ & $5.3 \pm 1.3$ & 0.056 \\
\hline $\mathrm{SV}, \mathrm{ml}$ & $117 \pm 35$ & $133 \pm 43$ & 0.21 \\
\hline $\mathrm{SVI}, \mathrm{ml} / \mathrm{m}^{2}$ & $64 \pm 21$ & $74 \pm 24$ & 0.063 \\
\hline PVC, $\mathrm{ml} / \mathrm{mm} \mathrm{Hg}$ & $4.5 \pm 3.1$ & $8.4 \pm 4.4$ & $<0.001$ \\
\hline PVR, dyn $\cdot s \cdot \mathrm{cm}^{-5}$ & $227 \pm 149$ & $72 \pm 37$ & $<0.001$ \\
\hline PVRI, dyn $\cdot s \cdot \mathrm{cm}^{-5} \cdot \mathrm{m}^{-2}$ & $417 \pm 264$ & $131 \pm 70$ & $<0.001$ \\
\hline $\mathrm{SVR}$, dyn $\cdot \mathrm{s} \cdot \mathrm{cm}^{-5}(\mathrm{n}=82)$ & $835 \pm 333$ & $740 \pm 254$ & 0.23 \\
\hline $\mathrm{Sv}_{\mathrm{O}_{2}} \%(\mathrm{n}=78)$ & $69 \pm 8$ & $73 \pm 9$ & 0.017 \\
\hline $\mathrm{TRV}, \mathrm{m} / \mathrm{s}$ & $3.3 \pm 0.5$ & $2.9 \pm 0.4$ & $<0.001$ \\
\hline $6 \mathrm{MWD}, \mathrm{m}(\mathrm{n}=80)$ & $358 \pm 115$ & $437 \pm 108$ & 0.00 \\
\hline $\mathrm{O}_{2}$ saturation, per unit $\%$ & $95 \pm 4$ & $97 \pm 3$ & 0.15 \\
\hline WHO FC III or IV, n (\%) & $18(33)$ & $4(14)$ & 0.07 \\
\hline
\end{tabular}

Definition of abbreviations: CVP = central venous pressure; $\mathrm{dPAP}=$ diastolic pulmonary artery pressure; $\mathrm{mPAP}=$ mean pulmonary artery pressure; PCWP $=$ pulmonary capillary wedge pressure; $\mathrm{PP}=$ pulmonary artery pulse pressure; PVC $=$ pulmonary artery capacitance; PVRI $=$ pulmonary vascular resistance index; SPAP = systolic pulmonary artery pressure; SV = stroke volume; SVI stroke volume index; $\mathrm{SV}_{\mathrm{O}_{2}}=$ mixed venous oxygen saturation; $\mathrm{SVR}=$ systemic vascular resistance; TPG = transpulmonary gradient; TRV = tricuspid regurgitant jet velocity; WHO FC $=$ World Health Organization functional class; 6MWD $=6$-min-walk distance.

*Data were summarized by the mean \pm SD and by frequency (percentage).

with $\mathrm{PH}$ had advanced World Health Organization functional class (WHO FC III or IV 33 vs. $14 \% ; P=0.07$ ) at the time of diagnosis compared with subjects with SCD without $\mathrm{PH}$. The exercise capacity was significantly limited in the SCD-PH group (6MWD $358 \pm 115$ vs. $437 \pm 108 \mathrm{~m} ; P=0.004$ ) compared with those without $\mathrm{PH}$.

Thirty-one $(5.9 \%$ of the 529 screened subjects; $56.4 \%$ of the subjects with $\mathrm{PH})$ had precapillary $\mathrm{PH}$, and 24 (4.5\% of the screened population; $43.6 \%$ of subjects with $\mathrm{PH}$ ) were diagnosed with postcapillary $\mathrm{PH}$, with mean values $\mathrm{mPAP}$ of $37 \pm 9 \mathrm{~mm} \mathrm{Hg}$ and PCWP $20 \pm 4 \mathrm{~mm} \mathrm{Hg}$. Hemodynamic values in subjects with precapillary $\mathrm{PH}$ included $\mathrm{mPAP}$ of $36 \pm 9 \mathrm{~mm} \mathrm{Hg}$, PCWP $12 \pm 3 \mathrm{~mm} \mathrm{Hg}$, transpulmonary gradient (TPG) $24 \pm 9 \mathrm{~mm} \mathrm{Hg}$ PVR $272 \pm 156 \mathrm{dyn} \cdot \mathrm{s} \cdot \mathrm{cm}^{-5}$, and CO $8.0 \pm 2.7 \mathrm{~L} / \mathrm{min}$ (Figure 1; Table E2). Sixteen of the 31 subjects with precapillary PH had a PVR of $240 \mathrm{dyn} \cdot \mathrm{s} \cdot \mathrm{cm}^{-5}$ or higher.

Even though subjects with SCD and PH have a less severe hemodynamic profile compared with other forms of precapillary $\mathrm{PH}$, functional capacity measures such as mean 6MWD and percentage of subjects in WHO functional class III and IV were severely abnormal, suggesting that even mild $\mathrm{PH}$ in adults with SCD is associated with significant functional impairment (Table E2). Both PH hemodynamic groups had worse functional capacity measured by 6MWD (postcapillary PH: $329 \pm 119 \mathrm{~m}[P<0.001]$; precapillary PH: $379 \pm 108 \mathrm{~m} ;[P<0.001])$ when compared with uncatheterized patients with SCD (485 $\pm 88 \mathrm{~m})$ (Tables E1and E2). Both of the PH subgroups showed significantly higher LDH levels (postcapillary PH: $473 \pm 247$ IU/L $[P=0.011]$; precapillary PH: $476 \pm 229 \mathrm{IU} / \mathrm{L}[P<0.001])$ compared with uncatheterized control subjects with SCD $(340 \pm 151 \mathrm{IU} / \mathrm{L})$ (Table E1). Subjects with postcapillary PH exhibited an elevated transpulmonary gradient (normal TPG $<12 \mathrm{~mm} \mathrm{Hg}$ ), suggesting a subgroup of these subjects have reactive postcapillary $\mathrm{PH}$.

\section{Survival and Risk Factors for Mortality}

Median follow-up time was 4.7 years, with a maximum followup of 11 years for all subjects alive, with $15 \%$ of enrolled subjects not yet due for biannual follow-up. A total of 77 deaths were observed. All-cause mortality was higher in patients with $\mathrm{PH}$ compared with patients without $\mathrm{PH}$ by $\mathrm{RHC}$ or the uncatheterized patients (log-rank test, $P<0.001)$. The 5-year mortality rates were $31.7,15.9$, and $14.4 \%$, respectively. Death certificates were available for 15 out of $23(65 \%)$ subjects with $\mathrm{PH}$, and $80 \%$ of these subjects were reported to have had right heart failure or sudden cardiac death stated as a cause of death.

To identify hemodynamic risk factors associated with mortality, survival estimates since catheterization for 84 subjects undergoing RHC were used. Survival estimates for the subjects with SCD and PH versus those subjects without PH by RHC were 89 versus $100 \%$ at 1 years, 76 versus $93 \%$ at 3 years, and 63 versus $83 \%$ at 5 years from diagnosis by RHC, respectively. The estimated median survival time was 6.8 years after RHC for subjects with SCD and PH. The survival was not different among the precapillary and postcapillary $\mathrm{PH}$ subgroups (log-rank test, $P=0.23$ ).

Several hemodynamic and laboratory variables were associated with mortality in the subjects undergoing RHC, particularly variables known to characterize severity of precapillary $\mathrm{PH}$. In the univariate Cox regression analysis of all potential predictors, sPAP, dPAP, mPAP, dPAP - PCWP, TPG, PVR, PVRI, phenotype, WHO FC, 6MWD, direct bilirubin, alkaline phosphatase, and serum ferritin level were significantly associated with mortality (Table 2). Kaplan-Meier survival estimates dichotomized by $\mathrm{mPAP} \geqslant 25 \mathrm{~mm} \mathrm{Hg}$, TPG $\geqslant 12 \mathrm{~mm} \mathrm{Hg}, 6 \mathrm{MWD}$, and $\mathrm{WHO}$ FC were statistically significant (Figure 2). The estimated unadjusted HRs for mortality were 3.02 (95\% CI, 1.04-8.76; $P=0.042)$ for $\mathrm{mPAP} \geqslant 25 \mathrm{~mm} \mathrm{Hg}, 3.55$ (95\% CI, 1.43-8.80; $P=0.003)$ for $\mathrm{TPG} \geqslant 12 \mathrm{~mm} \mathrm{Hg}, 2.68$ (95\% CI, 1.06-6.77; $P=0.031)$ for $6 \mathrm{MWD}<400 \mathrm{~m}$, and 3.64 (95\% CI, 1.65-8.05; $P<0.001)$ for WHO FC III-IV, compared with the corresponding counterpart of subjects undergoing RHC.

To adjust for potential confounding factors, age, gender, phenotype (SS vs. SC or S- $\beta$ thalassemia), hematocrit, hemoglobin $\mathrm{F}$, hemoglobin S, creatinine, direct bilirubin, and NT-proBNP were included in the multivariate Cox regression analyses of mortality and each of the hemodynamic variables. The mPAP (adjusted HR, 1.61 per $10 \mathrm{~mm} \mathrm{Hg}$; 95\% CI, 1.05-2.45; $P=$ 0.027), dPAP (adjusted HR, 1.83 per $10 \mathrm{~mm} \mathrm{Hg}$; 95\% CI, 1.09-3.08; $P=0.022$ ), TPG (adjusted HR, 1.78 per $10 \mathrm{~mm} \mathrm{Hg}$; 95\% CI, 1.14-2.79; $P=0.011$ ), PVR (HR, 1.44 per Wood unit; 95\% CI, 1.09-1.89; $P=0.009$ ), and dPAP - PCWP (adjusted HR, 2.19 per $10 \mathrm{~mm} \mathrm{Hg}$; 95\% CI, 1.23-3.89; $P=0.008$ ) were predictive in a multivariate model, and sPAP was borderline significant (Table 3). The five multivariate models had comparable AIC values, suggesting that they had similar goodness of fit and the five hemodynamic variables had nearly equal HR for mortality controlling for multiple risk factors. Moreover, mPAP, TPG, and PVR were dichotomized around their median values $(\mathrm{mPAP} \geqslant 28 \mathrm{~mm} \mathrm{Hg}, \mathrm{TPG} \geqslant 12 \mathrm{~mm} \mathrm{Hg}$, and PVR $\geqslant$ $\left.115 \mathrm{dyn} \cdot \mathrm{s} \cdot \mathrm{cm}^{-5}\right)$, respectively, and each of these dichotomized variables was statistically significant in the multivariate model (Table 3). Sickle cell variant phenotype was also a significant predictor of all-cause mortality in each of the multivariate models. Similar results were obtained when the analysis was limited to the 55 patients with PH (Table E3). Other factors were not statistically significant in the multivariate models, and the addition 
TABLE 2. UNIVARIATE ANALYSIS FOR MORTALITY RISK FACTORS

\begin{tabular}{|c|c|c|}
\hline Characteristic $(N=84)$ & Unadjusted HR $(95 \% \mathrm{Cl})$ & $P$ Value \\
\hline Age, per $10 \mathrm{yr}$ & $1.02(0.76-1.38)$ & 0.89 \\
\hline Phenotype (SS vs. SC or $S-\beta$ thalassemia) & $5.90(1.01-43.6)$ & 0.048 \\
\hline sPAP, per $10 \mathrm{~mm} \mathrm{Hg}$ & $1.30(1.06-1.58)$ & 0.009 \\
\hline dPAP, per $10 \mathrm{~mm} \mathrm{Hg}$ & $1.91(1.25-2.92)$ & 0.002 \\
\hline mPAP, per $10 \mathrm{~mm} \mathrm{Hg}$ & $1.62(1.17-2.24)$ & 0.003 \\
\hline TPG, per $10 \mathrm{~mm} \mathrm{Hg}$ & $1.82(1.28-2.61)$ & $<0.001$ \\
\hline PVR, per 1 Wood Unit & $1.35(1.11-1.65)$ & 0.002 \\
\hline PVRI, per 1 Wood Unit $/ \mathrm{m}^{2}$ & $1.20(1.08-1.33)$ & $<0.001$ \\
\hline $\mathrm{PP}$, per $10 \mathrm{~mm} \mathrm{Hg}$ & $1.29(0.96-1.73)$ & 0.091 \\
\hline dPAP-PCWP, per $10 \mathrm{~mm} \mathrm{Hg}$ & $2.26(1.43-3.58)$ & $<0.001$ \\
\hline CVP, per $10 \mathrm{~mm} \mathrm{Hg}(\mathrm{n}=83)$ & $1.36(0.65-2.83)$ & 0.42 \\
\hline PCWP, per $10 \mathrm{~mm} \mathrm{Hg}$ & $0.97(0.47-2.02)$ & 0.93 \\
\hline Cardiac output, L/min & $0.98(0.85-1.13)$ & 0.74 \\
\hline Cardiac index, $L \cdot \min ^{-1} \cdot \mathrm{m}^{-2}$ & $0.87(0.66-1.13)$ & 0.29 \\
\hline $\mathrm{SV}_{\mathrm{O}_{2}}, \%(\mathrm{n}=78)$ & $0.98(0.94-1.03)$ & 0.42 \\
\hline $6 \mathrm{MWD}$, per $100 \mathrm{~m}(\mathrm{n}=80)$ & $0.56(0.39-0.79)$ & $<0.001$ \\
\hline Oxygen saturation, per unit $\%$ & $0.93(0.85-1.02)$ & 0.12 \\
\hline WHO FC (III-IV vs. I-II) & $3.64(1.64-8.05)$ & $<0.001$ \\
\hline Creatinine, $\mathrm{mg} / \mathrm{dl}$ & $1.09(0.71-1.69)$ & 0.69 \\
\hline Alkaline phosphatase, U/L per 100 & $1.71(1.14-2.56)$ & 0.008 \\
\hline Bilirubin, direct, $\mathrm{mg} / \mathrm{dl}$ & $1.63(1.07-2.48)$ & 0.018 \\
\hline Ferritin, $\mu \mathrm{g} / \mathrm{L}$ per $1,000(\mathrm{n}=83)$ & $1.26(1.04-1.53)$ & 0.016 \\
\hline Ferritin, $>1,000 \mu \mathrm{g} / \mathrm{L}(\mathrm{n}=83)$ & $2.39(1.11-5.14)$ & 0.02 \\
\hline
\end{tabular}

Definition of abbreviations: $\mathrm{CVP}=$ central venous pressure; $\mathrm{dPAP}=$ diastolic pulmonary artery pressure; $\mathrm{dPAP}-\mathrm{PCWP}=$ diastolic pulmonary artery pressure minus pulmonary capillary wedge pressure; $\mathrm{mPAP}=$ mean pulmonary artery pressure; $\mathrm{PCWP}=$ pulmonary capillary wedge pressure; $\mathrm{PP}=$ pulmonary artery pulse pressure; $\mathrm{PVR}=$ pulmonary vascular resistance; PVRI = pulmonary vascular resistance index; 6MWD = 6-min-walk distance; $\mathrm{SPAP}=$ systolic pulmonary artery pressure; $\mathrm{TPG}=$ transpulmonary gradient; WHO FC $=$ World Health Organization functional class.

of other hemodynamic variables such as CI, CO, PCWP, SV, SVI, PVC, and SVR to the model produced virtually no change in the results.

\section{Histopathology}

Six of the patients with $\mathrm{PH}$ who died underwent postmortem examination. The mean time from RHC to death in these subjects was 3.23 years (range, $0.07-7.91 \mathrm{yr}$ ). Mean mPAP was $41 \mathrm{~mm} \mathrm{Hg}$ (range, 28-51 mm Hg), mean TPG was $26 \mathrm{~mm} \mathrm{Hg}$ (range, 1236), mean PVR was $273 \mathrm{dyn} \cdot \mathrm{s} \cdot \mathrm{cm}^{-5}$ (range, 93-661), mean $\mathrm{Sv}_{\mathrm{O}_{2}}$ was $68 \%$ (range, 63-74), and mean 6MWD was $261 \mathrm{~m}$ (range, 126-399). Four out of the six subjects had precapillary $\mathrm{PH}$, and two had postcapillary $\mathrm{PH}$, one of which had a TPG of $24 \mathrm{~mm} \mathrm{Hg}$ and PVR of $300 \mathrm{dyn} \cdot \mathrm{s} \cdot \mathrm{cm}^{-5}$. Histopathologic examination showed dilated pulmonary arteries, widespread and extensive vascular changes with moderate to severe medial proliferation, and intimal thickening associated with grade III-IV plexiform lesions (31) in their pulmonary arteries (Figure 3).

\section{DISCUSSION}

There has been controversy regarding the prevalence of $\mathrm{PH}$ in SCD and its contribution to mortality $(21,22,24)$. Our recent publication on this same cohort has documented the linkage of catheterization-proven pulmonary hypertension to mortality in adults with SCD. What this study adds to the literature is significant epidemiological evidence that mortality is proportional to several specific gold standard hemodynamic markers of severity of precapillary $\mathrm{PH}$ pathophysiology, such as PVR and TPG. Our new results also deemphasize the mortality significance of PCWP, a marker of postcapillary PH and left ventricular disease. Although a prospective registry study cannot prove the etiology of death in this cohort, this finding supports precapillary $\mathrm{PH}$ as a risk factor for early mortality in adults with SCD. Furthermore, by providing a detailed analysis of our previously published data from this cohort, we show that the mortality rate is proportional to the severity of $\mathrm{PH}$ as indicated by all measures of pulmonary artery disease, highlighted by the robust association of mortality to multiple physiologic

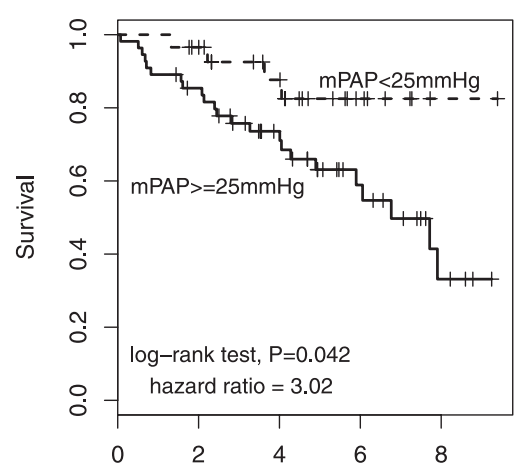

Years after right heart catheterization

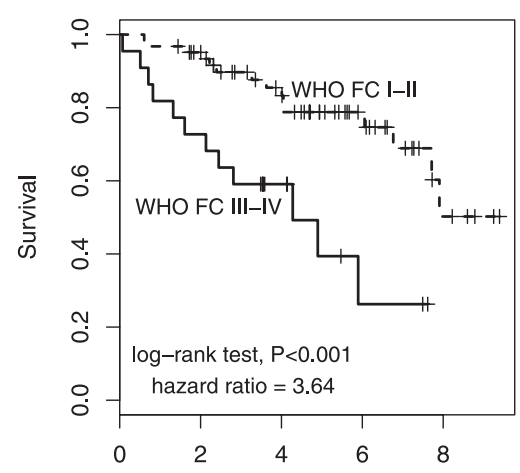

Years after right heart catheterization

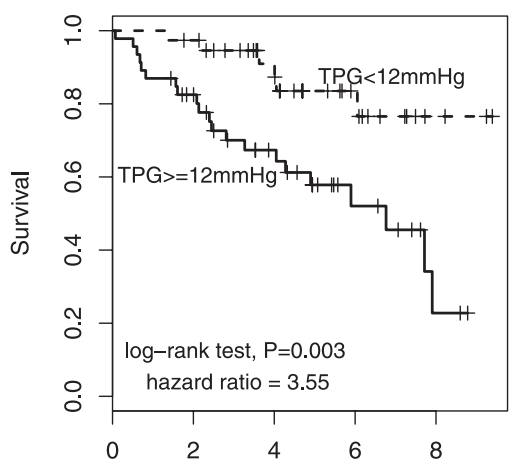

Years after right heart catheterization

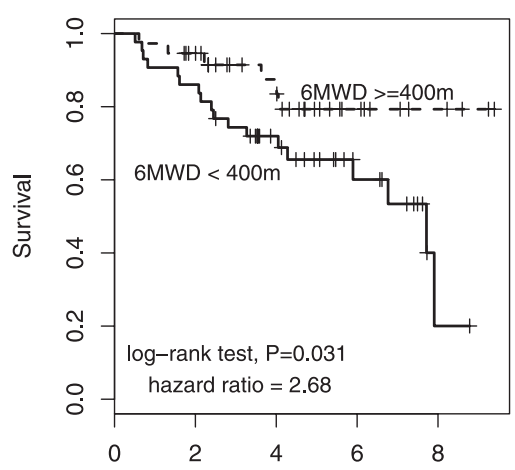

Years after right heart catheterization
Figure 2. Kaplan-Meier survival curves after right heart catheterization for important clinical variables in adults with sickle cell disease. Curves indicate survival in years after catheterization for 84 adults with sickle cell disease. Significant differences in survival are observed subjects with mean pulmonary artery pressure (mPAP) $\geqslant 25 \mathrm{~mm} \mathrm{Hg}$ (upper left) and transpulmonary gradient (TPG) $\geqslant 12 \mathrm{~mm} \mathrm{Hg}$ (upper right), advanced World Health Organization Functional Class (WHO FC III or IV, lower left), or 6-minute walk distance $(6 \mathrm{MWD})<400 \mathrm{~m}$ (lower right). 
TABLE 3. MULTIVARIATE ANALYSIS FOR MORTALITY RISK FACTORS

\begin{tabular}{|c|c|c|c|c|}
\hline Models* & Variable & $\begin{array}{c}\text { Adjusted HR } \\
(95 \% \mathrm{Cl})\end{array}$ & $P$ Value & $\mathrm{AIC}^{\dagger}$ \\
\hline 1 & mPAP, per $10 \mathrm{~mm} \mathrm{Hg}$ & $1.61(1.05-2.45)$ & 0.027 & 192.4 \\
\hline 2 & dPAP, per $10 \mathrm{~mm} \mathrm{Hg}$ & $1.83(1.09-3.08)$ & 0.022 & 192.1 \\
\hline 3 & dPAP - PCWP, per $10 \mathrm{~mm} \mathrm{Hg}$ & $2.19(1.23-3.89)$ & 0.008 & 190.2 \\
\hline 4 & TPG, per $10 \mathrm{~mm} \mathrm{Hg}$ & $1.78(1.14-2.79)$ & 0.011 & 190.9 \\
\hline 5 & PVR, per Wood unit & $1.44(1.09-1.89)$ & 0.009 & 190.5 \\
\hline \multirow[t]{2}{*}{6} & sPAP, per $10 \mathrm{~mm} \mathrm{Hg}$ & $1.30(0.99-1.71)$ & 0.055 & 193.6 \\
\hline & Dichotomized Variable by Median & & & \\
\hline I & $\mathrm{mPAP} \geqslant 28 \mathrm{~mm} \mathrm{Hg}$ & $4.76(1.45-15.7)$ & 0.010 & 189.5 \\
\hline II & $\mathrm{TPG} \geqslant 12 \mathrm{~mm} \mathrm{Hg}$ & $3.19(1.13-9.01)$ & 0.029 & 192.1 \\
\hline III & $\mathrm{PVR} \geqslant 115 \mathrm{dyn} \cdot \mathrm{s} \cdot \mathrm{cm}^{-5}$ & $3.41(1.15-10.1)$ & 0.027 & 192.0 \\
\hline
\end{tabular}

Definition of abbreviations: $\mathrm{Cl}=$ confidence interval; dPAP $=$ diastolic pulmonary artery pressure; $\mathrm{dPAP}-\mathrm{PCWP}=$ diastolic pulmonary artery pressure minus pulmonary capillary wedge pressure; $\mathrm{HR}=$ hazard ratio; $\mathrm{mPAP}=$ mean pulmonary artery pressure; $P C W P=$ pulmonary capillary wedge pressure; $\mathrm{PP}=$ pulmonary artery pulse pressure; $\mathrm{PVR}=$ pulmonary vascular resistance $6 \mathrm{MWD}=6$ - $\mathrm{min}$-walk distance; $\mathrm{sPAP}=$ systolic pulmonary artery pressure TPG $=$ transpulmonary gradient

*Age, gender, phenotype (SS vs. SC/ $\beta$-thalassemia), hematocrit, hemoglobin $\mathrm{F}$, hemoglobin $\mathrm{S}, \mathrm{N}$-terminal prohormone of brain natriuretic peptide (NTproBNP), creatinine, and direct bilirubin were included in each of the multivariate Cox regression models. Two patients with missing NT-proBNP were excluded.

${ }^{\dagger}$ The Akaike information criterion (AIC) was used to compare different regression models. The models with smaller AIC have better fit to the data.

indicators of precapillary PH severity, including the PVR, TPG, and the gradient between pulmonary arterial diastolic and PCWP. In fact, we find that sPAP, PP, TPG, and PVR were nearly equally and independently associated with mortality when combined with the previously established SCD mortality serum biomarkers creatinine, alkaline phosphatase, and ferritin. These results emphasize that mortality rate in adults with SCD is proportional to the severity of precapillary $\mathrm{PH}$. Consistent with this observation, patients with SCD with
$\mathrm{PH}$ can have histopathological changes more severe than might be expected from relatively modest hemodynamic abnormalities (Figure 3).

Left ventricular dysfunction, characterized by markers of diastolic heart failure, is frequently encountered in adults with SCD and has been associated with risk of mortality additive to echocardiographic markers of PH (33). In our cohort, these subjects are represented by the postcapillary subgroup. Although the postcapillary $\mathrm{PH}$ subgroup shares a high mortality rate, the PCWP is not significant as a predictor of mortality, suggesting that precapillary $\mathrm{PH}$ physiology dominates mortality risk in SCD. Consistent with this interpretation, the mean TPG is above $12 \mathrm{~mm} \mathrm{Hg}$ in the postcapillary $\mathrm{PH}$ group, suggesting that even the postcapillary $\mathrm{PH}$ group shares some physiological characteristics of the precapillary remodeling. Likely our catheterized cohort lacks sufficient statistical power to characterize potentials interaction between precapillary $\mathrm{PH}$ and postcapillary $\mathrm{PH}$ upon prognosis, as previously suggested (33). However, RHC physiologic markers of left ventricular dysfunction in adults with SCD and PH appear to have less prognostic significance than those of precapillary $\mathrm{PH}$.

Our findings are in agreement with previous studies describing the hemodynamic etiology of $\mathrm{PH}$ in SCD as heterogeneous $(8,9)$. Our findings are similar to a French study that classified its adult subjects as $46 \%$ precapillary (11/24) and $54 \%$ postcapillary among subjects with SCD and $\mathrm{PH}(8)$. Unlike the French study, which reported $\mathrm{PH}$ in only $25 \%$ of subjects who underwent RHC $(\mathrm{n}=96)$ and in $6 \%$ in the whole screened cohort $(\mathrm{n}=385)$, we found prevalence of $\mathrm{PH}$ of all types of $65.5 \%(55 /$ $84)$ in those who underwent RHC or $10.4 \%(55 / 531)$ in our screened cohort. These differences may be related in part to the French protocol including all subjects with TRV $\geqslant 2.5 \mathrm{~m} / \mathrm{s}$ regardless of $6 \mathrm{MW}$ but also their exclusion of subjects with liver dysfunction, chronic renal insufficiency, or low total lung capacity. Exclusion of these subjects likely underestimated the true prevalence of $\mathrm{PH}$ because markers of renal insufficiency,

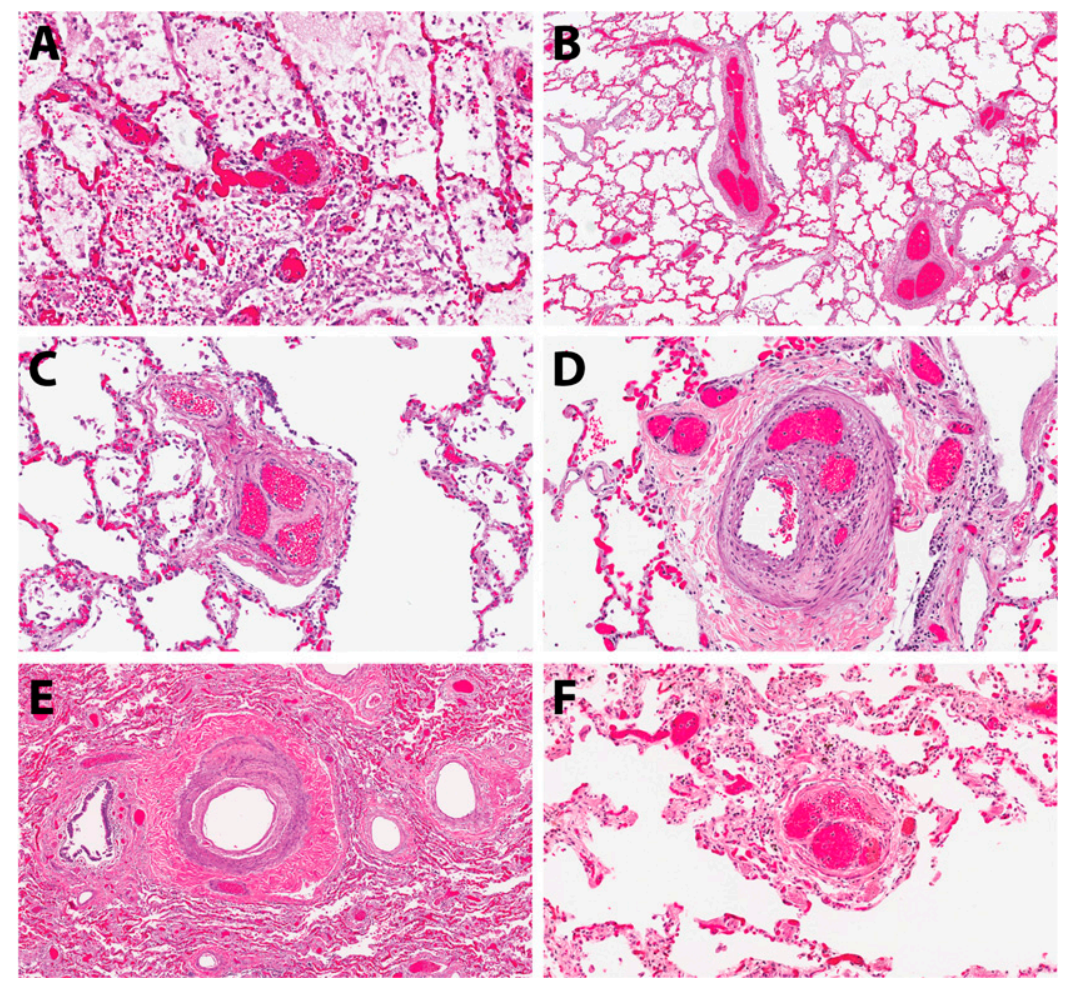

Figure 3. Pulmonary vascular pathology in patients with sickle cell disease (SCD). Microscopic examination of lung tissue reveals widespread proliferative arteriopathy, vascular changes, and thrombosis consistent with pulmonary arterial hypertension. Representative photomicrographs from six patients with SCD who died and underwent autopsy in this study show dilated vasculature, medial hypertrophy, intimal proliferation of pulmonary arteries, and numerous complex plexiform lesions scattered throughout the lung parenchyma. (A) A 54-year-old man with mean pulmonary artery pressure (mPAP) of $31 \mathrm{~mm} \mathrm{Hg}$ and pulmonary vascular resistance (PVR) of $105 \mathrm{dyn} \cdot \mathrm{s} \cdot \mathrm{cm}^{-5}$ who died with pneumonia. (B) A 30-year-old man with mPAP of $28 \mathrm{~mm} \mathrm{Hg}$ and PVR of $226 \mathrm{dyn} \cdot \mathrm{s} \cdot \mathrm{cm}^{-5}$ who died with acute cor pulmonale during acute chest syndrome. (C) A 44-year-old woman with mPAP of $51 \mathrm{~mm} \mathrm{Hg}$ and PVR of $830 \mathrm{dyn} \cdot \mathrm{s} \cdot \mathrm{cm}^{-5}$; sudden death at home. (D) A 35-year-old man with mPAP of $44 \mathrm{~mm} \mathrm{Hg}$ and PVR of 366 dyn $\cdot \mathrm{s} \cdot \mathrm{cm}^{-5}$; sudden death at home. (E) A 54-year-old man with mPAP of $51 \mathrm{~mm} \mathrm{Hg}$ and PVR of $285 \mathrm{dyn} \cdot \mathrm{s} \cdot \mathrm{cm}^{-5}$ who died of hepatic cirrhosis complicating progressive right heart failure. $(F)$ A 48-year-old woman with mPAP of $41 \mathrm{~mm} \mathrm{Hg}$ PVR of $300 \mathrm{dyn} \cdot \mathrm{s} \cdot \mathrm{cm}^{-5}$ who died of right heart failure decompensated by sepsis-related bone marrow embolism. The micrographs illustrate the severity of histopathologic findings of pulmonary arterial hypertension in SCD that is often much greater than might be expected for the degree of hemodynamic abnormality. 
hepatic dysfunction, and iron overload are independent risk factors for high estimated pulmonary artery pressure in patients with SCD $(3,4)$. The French study appeared to apply RHC to a larger proportion of subjects with normal pulmonary pressure because in our cohort subjects with RHC-proven PH had mPAP of $37 \pm$ $9 \mathrm{~mm} \mathrm{Hg}$, compared with their mPAP of $30 \pm 0.46 \mathrm{~mm} \mathrm{Hg}$. Given that our study had no exclusion criteria, the prevalence rate of $10.4 \%$ is likely to be more accurate. Our prevalence rates are consistent with a recent screening study from Brazil (34).

The $10.4 \%$ prevalence of $\mathrm{PH}$ and the prevalence of precapillary $\mathrm{PH}$ of $6 \%$ in adults with SCD from the largest cohort of prospectively identified subjects with SCD and $\mathrm{PH}$ ranks highly among populations predisposed to $\mathrm{PH}$. This prevalence would place SCD as second only to scleroderma (12\%) among associated conditions under WHO group I precapillary $\mathrm{PH}(35,36)$ and comparable to portopulmonary hypertension (1-6\%) (37) and HIV infection (0.5\%) (38).

$\mathrm{PH}$ associated with SCD is characterized by relatively modest elevations of mPAP and PVR and a high cardiac output, as seen in this study and others $(9,10)$. Despite these seemingly favorable hemodynamic findings, subjects with SCD and PH have a marked reduction in their functional capacity and high mortality, suggesting that any level of PH in these severely anemic patients portends a poor prognosis. Several echocardiographic studies have reported that subjects with SCD and a high estimated sPAP have a poor prognosis, with HRs for death ranging from 4.4 to $10(2-4,6,20)$. We currently find greater median survival in SCD-PH of 6.8 years compared with Castro's report in symptomatic subjects of 2.1 years (10). This improved survival might arise from several possible reasons. Presymptomatic screening in our study may be leading to case ascertainment at an earlier age and stage of disease. A much larger number of therapies approved for $\mathrm{PH}$ in the general population have become available over the intervening years, potentially permitting better PH control. Last, supportive care of SCD with hydroxyurea or chronic transfusion has been more aggressively promoted in the last decade, and anecdotal evidence indicates that in some cases this may lead to better control of pulmonary arterial pressures $(39,40)$.

At their usual baseline, due to their high cardiac output, subjects with SCD with normal mPAP have PVR between 22 and $62 \mathrm{dyn} \cdot \mathrm{s} \cdot \mathrm{cm}^{-5}(11)$. Although PVR is useful, the current precapillary $\mathrm{PH}$ classification does not require it as a diagnostic criterion $(1,41)$. PVR values may not adequately characterize pulmonary vascular disease in the severely anemic population because the associated high cardiac output induces a compensatory decrease in PVR, and the low blood viscosity of anemia reduces developed pressure at any given rate of flow.

Our study reports hemodynamic markers of $\mathrm{PH}$ severity as risk factors for poor survival in SCD. Caution is required in comparisons with pulmonary arterial hypertension in other populations in which cardiac output or stroke volume is associated with risk of mortality. In subjects with idiopathic pulmonary arterial hypertension, the NIH registry suggested that three hemodynamic variables (increased PAP, increased CVP, and decreased cardiac index) predicted increased risk of death (26). Although we observed trends in our analyses, some of these traditional hemodynamic parameters were not independently associated with mortality in our cohort, suggesting that there may be a different mode of demise in SCD-PH. Another potential explanation for these findings would be the high variability observed in the data related to right ventricular function given the confounding effects of anemia on cardiac output and filling pressures. Additionally, the acute increase in pulmonary artery pressure in the sickle cell vasoocclusive pain crisis (42) and the acute chest syndrome associated with mortality (43) might be more likely to be lethal in these patients with SCD and PH with diminished functional reserve. Finally, TPG and PVR are independent risk factors for death, suggesting that these measures may be more relevant indices of pulmonary vascular dysfunction in patients with SCD and $\mathrm{PH}$. Not surprisingly, rising mPAP was proportional to survival. Subjects with $\mathrm{mPAP} \geqslant 28 \mathrm{~mm} \mathrm{Hg}$ (median value in our RHC cohort) had 4.8-fold higher hazard of dying compared with those with a mPAP $<28 \mathrm{~mm} \mathrm{Hg}$. The hazard increased by 1.6 for every $10 \mathrm{~mm} \mathrm{Hg}$ increase in mPAP. Similarly, Castro and colleagues reported that each $10 \mathrm{~mm} \mathrm{Hg}$ increase in mPAP was associated with a 1.7-fold increase in death rate (10). The prognostic value of PVR and TPG is shared with scleroderma-associated precapillary $\mathrm{PH}$ (44), $\mathrm{PH}$ after heart transplantation (45), and portopulmonary hypertension after liver transplantation (46).

Our results confirm several associations previously described in adults with SCD with echocardiographic-estimated high pulmonary artery pressure. Lower hemoglobin and hematocrit and higher serum levels of AST and LDH than the general sickle cell control group in this study are associated with $\mathrm{PH}$ proven by $\mathrm{RHC}$, as seen previously with echocardiography (2-4, 47-50). These markers have also been linked to accelerated hemolysis and alterations in nitric oxide bioavailability $(48,51)$. Alkaline phosphatase and ferritin were elevated in subjects with SCD with $\mathrm{PH}$ and were risk factors for death in the univariate and multivariate analyses, confirming previous findings from echocardiography (4). Another previously identified risk factor, direct bilirubin, reflects an association observed in precapillary PH without SCD (52). Increasing age is reported with an increased risk of $\mathrm{PH}$ in previous studies $(2,4)$, but mortality was not explained by old age among patients with $\mathrm{PH}$ in our study. Our results indicate that subjects with SCD and PH had 3-fold increased risk for death than subjects with SCD of similar age who were documented by RHC not to have $\mathrm{PH}$.

A number of limitations must be noted. First, our registry study was performed in a single center, with a retrospective analysis of prevalent and incident cases. As a consequence, survival rates might have been overestimated and the prevalence of $\mathrm{PH}$ could have been overestimated due to referral bias. Additional limitations are the observational nature of our findings and our inability to draw conclusions regarding cause and effect. Because RHC was not performed in every subject initially screened for $\mathrm{PH}$, we cannot calculate the precise sensitivity and specificity of TRV as a predictor of $\mathrm{PH}$ by RHC.

\section{Conclusions}

$\mathrm{PH}$ documented by RHC is strongly associated with worse functional capacity and increased risk of death in adults with SCD. Several measures of precapillary disease severity are independently associated with survival in this cohort. Multifactorial pathophysiologic pathways likely play a combined role in SCD-PH, but our data provide definitive physiological evidence that, despite the atypical hemodynamic features imparted by the compensatory response to severe anemia in SCD, the dominant features of precapillary $\mathrm{PH}$, including $\mathrm{MPAP}, \mathrm{PVR}$, and TPG, are proportional to the poor prognosis in catheterized patients with SCD and PH. Additional clinical research with intervention targeted at precapillary $\mathrm{PH}$ is warranted in this complex and high-risk population.

Author disclosures are available with the text of this article at www.atsjournals.org.

Acknowledgment: The authors acknowledge Dr. Mark T. Gladwin for many helpful discussions. The authors thank Mary K. Hall for expert protocol management, the protocol coordinators who contributed to this study (James Nichols, Wynona Coles, and Lori Hunter), and the patients with sickle cell disease who participated in this study. 


\section{References}

1. Badesch DB, Champion HC, Gomez Sanchez MA, Hoeper MM, Loyd JE, Manes A, McGoon M, Naeije R, Olschewski H, Oudiz RJ, et al. Diagnosis and assessment of pulmonary arterial hypertension. $J$ Am Coll Cardiol 2009;54:S55-S66.

2. Ataga KI, Moore CG, Jones S, Olajide O, Strayhorn D, Hinderliter A, Orringer EP. Pulmonary hypertension in patients with sickle cell disease: a longitudinal study. Br J Haematol 2006;134:109-115.

3. De Castro LM, Jonassaint JC, Graham FL, Ashley-Koch A, Telen MJ. Pulmonary hypertension associated with sickle cell disease: clinical and laboratory endpoints and disease outcomes. Am J Hematol 2008;83:19-25.

4. Gladwin MT, Sachdev V, Jison ML, Shizukuda Y, Plehn JF, Minter K, Brown B, Coles WA, Nichols JS, Ernst I, et al. Pulmonary hypertension as a risk factor for death in patients with sickle cell disease. $N$ Engl J Med 2004;350:886-895.

5. Powars D, Weidman JA, Odom-Maryon T, Niland JC, Johnson C. Sickle cell chronic lung disease: prior morbidity and the risk of pulmonary failure. Medicine 1988;67:66-76.

6. Sutton LL, Castro O, Cross DJ, Spencer JE, Lewis JF. Pulmonary hypertension in sickle cell disease. Am J Cardiol 1994;74:626-628.

7. Mehari A, Gladwin MT, Tian X, Machado RF, Kato GJ. Mortality in adults with sickle cell disease and pulmonary hypertension. JAMA 2012;307:1254-1256.

8. Parent F, Bachir D, Inamo J, Lionnet F, Driss F, Loko G, Habibi A, Bennani S, Savale L, Adnot S, et al. A hemodynamic study of pulmonary hypertension in sickle cell disease. $N$ Engl J Med 2011;365:44-53.

9. Anthi A, Machado RF, Jison ML, Taveira-Dasilva AM, Rubin LJ, Hunter L, Hunter CJ, Coles W, Nichols J, Avila NA, et al. Hemodynamic and functional assessment of patients with sickle cell disease and pulmonary hypertension. Am J Respir Crit Care Med 2007;175: 1272-1279.

10. Castro O, Hoque M, Brown BD. Pulmonary hypertension in sickle cell disease: cardiac catheterization results and survival. Blood 2003;101: 1257-1261.

11. Leight L, Snider TH, Clifford GO, Hellems HK. Hemodynamic studies in sickle cell anemia. Circulation 1954;10:653-662.

12. Parent F, Bachir D, Lionnet F, Inamo J, Driss F, Savale L, Loko G, Elmazouzi A, Letierce A, Girot R, et al. Prevalence and mechanism of pulmonary hypertension in sickle cell disease: a prospective multicentre french study. Am J Respir Crit Care Med 2009;179:A2646.

13. Grupo de Trabalho para o Diagnóstico e Tratamento da Hipertensão Pulmonar da European Society of Cardiology. [Guidelines for the diagnosis and treatment of pulmonary hypertension]. Rev Port Cardiol 2012;31:71-115.

14. Chemla D, Castelain V, Herv ÃP, Lecarpentier Y, Brimioulle S. Haemodynamic evaluation of pulmonary hypertension. Eur Respir J 2002; 20:1314-1331.

15. Haque AK, Gokhale S, Rampy BA, Adegboyega P, Duarte A, Saldana MJ. Pulmonary hypertension in sickle cell hemoglobinopathy: a clinicopathologic study of 20 cases. Hum Pathol 2002;33:1037-1043.

16. Graham JK, Mosunjac M, Hanzlick RL. Sickle cell lung disease and sudden death: a retrospective/prospective study of 21 autopsy cases and literature review. Am J Forensic Med Pathol 2007;28:168-172.

17. Collins FS, Orringer EP. Pulmonary hypertension and cor pulmonale in the sickle hemoglobinopathies. Am J Med 1982;73:814-821.

18. Manci EA, Culberson DE, Yang YM, Gardner TM, Powell R, Haynes J Jr, Shah AK, Mankad VN. Causes of death in sickle cell disease: an autopsy study. Br J Haematol 2003;123:359-365.

19. Voelkel NF, Quaife RA, Leinwand LA, Barst RJ, McGoon MD, Meldrum DR, Dupuis J, Long CS, Rubin LJ, Smart FW, et al. Right ventricular function and failure: report of a national heart, lung, and blood institute working group on cellular and molecular mechanisms of right heart failure. Circulation 2006;114:1883-1891.

20. Lorch D, Spevack D, Little J. An elevated estimated pulmonary arterial systolic pressure, whenever measured, is associated with excess mortality in adults with sickle cell disease. Acta Haematol 2011;125:225-229.

21. Hebbel RP. Reconstructing sickle cell disease: a data-based analysis of the "hyperhemolysis paradigm" for pulmonary hypertension from the perspective of evidence-based medicine. Am J Hematol 2011;86:123-154.

22. Bunn HF, Nathan DG, Dover GJ, Hebbel RP, Platt OS, Rosse WF, Ware RE. Pulmonary hypertension and nitric oxide depletion in sickle cell disease. Blood 2010;116:687-692.
23. Nathan DG. Guilt by association. Blood 2011;118:3758-3759.

24. Simonneau G, Parent F. Pulmonary hypertension in patients with sickle cell disease: not so frequent but so different. Eur Respir J 2012;39:3-4.

25. Fonseca GH, Souza R, Salemi VM, Jardim CV, Gualandro SF. Pulmonary hypertension diagnosed by right heart catheterisation in sickle cell disease. Eur Respir J 2012;39:112-118.

26. D’Alonzo GE, Barst RJ, Ayres SM, Bergofsky EH, Brundage BH, Detre KM, Fishman AP, Goldring RM, Groves BM, Kernis JT, et al. Survival in patients with primary pulmonary hypertension: results from a national prospective registry. Ann Intern Med 1991;115:343-349.

27. McLaughlin VV, Shillington A, Rich S. Survival in primary pulmonary hypertension: the impact of epoprostenol therapy. Circulation 2002; 106:1477-1482

28. Sitbon O, Humbert M, Nunes H, Parent F, Garcia G, Hervé P, Rainisio M, Simonneau G. Long-term intravenous epoprostenol infusion in primary pulmonary hypertension: prognostic factors and survival. J Am Coll Cardiol 2002;40:780-788.

29. Miyamoto S, Nagaya N, Satoh T, Kyotani S, Sakamaki F, Fujita M, Nakanishi N, Miyatake K. Clinical correlates and prognostic significance of six-minute walk test in patients with primary pulmonary hypertension: comparison with cardiopulmonary exercise testing. $A m$ J Respir Crit Care Med 2000;161:487-492.

30. Benza RL, Miller DP, Gomberg-Maitland M, Frantz RP, Foreman AJ, Coffey CS, Frost A, Barst RJ, Badesch DB, Elliott CG, et al. Predicting survival in pulmonary arterial hypertension: insights from the registry to evaluate early and long-term pulmonary arterial hypertension disease management (reveal). Circulation 2010;122:164-172.

31. Mehari A, Tian X, Alam S, Xu D, Seamon C, Gladwin MT, Machado RF, Kato GJ. Hemodynamic parameters predict mortality in sickle cell disease-related pulmonary hypertension. ASH Annual Meeting Abstracts. Blood 2010;116:2668.

32. Simonneau G. A new clinical classification of pulmonary hypertension [in French]. Bull Acad Natl Med 2009;193:1897-1909.

33. Sachdev V, Machado RF, Shizukuda Y, Rao YN, Sidenko S, Ernst I, St Peter M, Coles WA, Rosing DR, Blackwelder WC, et al. Diastolic dysfunction is an independent risk factor for death in patients with sickle cell disease. J Am Coll Cardiol 2007;49:472-479.

34. Fonseca G, Souza R, Salemi V, Jardim CVP, Gualandro S. Pulmonary hypertension diagnosed by right heart catheterization in sickle cell disease. Eur Respir $J$ (in press)

35. Mukerjee D, St George D, Coleiro B, Knight C, Denton CP, Davar J, Black CM, Coghlan JG. Prevalence and outcome in systemic sclerosis associated pulmonary arterial hypertension: application of a registry approach. Ann Rheum Dis 2003;62:1088-1093.

36. Sitbon O, Jais X, Le Pavec J, Degano B, Humbert M, Simonneau G. Pulmonary arterial hypertension associated with common diseases: connective-tissue diseases, HIV infection and portal hypertension [in French]. Rev Prat 2008;58:2011-2018.

37. Kawut SM, Taichman DB, Ahya VN, Kaplan S, Archer-Chicko CL, Kimmel SE, Palevsky HI. Hemodynamics and survival of patients with portopulmonary hypertension. Liver Transpl 2005;11:1107-1111.

38. Sitbon O, Lascoux-Combe C, Delfraissy JF, Yeni PG, Raffi F, De Zuttere D, Gressin V, Clerson P, Sereni D, Simonneau G. Prevalence of hivrelated pulmonary arterial hypertension in the current antiretroviral therapy era. Am J Respir Crit Care Med 2008;177:108-113.

39. Olnes M, Chi A, Haney C, May R, Minniti C. Taylor J VI, Kato GJ. Improvement in hemolysis and pulmonary arterial systolic pressure in adult patients with sickle cell disease during treatment with hydroxyurea. Am J Hematol 2009;84:530-532.

40. Pashankar FD, Carbonella J, Bazzy-Asaad A, Friedman A. Longitudinal follow up of elevated pulmonary artery pressures in children with sickle cell disease. Br J Haematol 2009;144:736-741.

41. Simonneau G, Robbins IM, Beghetti M, Channick RN, Delcroix M, Denton CP, Elliott CG, Gaine SP, Gladwin MT, Jing ZC, et al. Updated clinical classification of pulmonary hypertension. J Am Coll Cardiol 2009;54:S43-S54.

42. Machado RF, Mack AK, Martyr S, Barnett C, Macarthur P, Sachdev V, Ernst I, Hunter LA, Coles WA, Nichols JP, et al. Severity of pulmonary hypertension during vaso-occlusive pain crisis and exercise in patients with sickle cell disease. Br J Haematol 2007;136:319-325.

43. Mekontso Dessap A, Leon R, Habibi A, Nzouakou R, Roudot-Thoraval F, Adnot S, Godeau B, Galacteros F, Brun-Buisson C, Brochard L, 
et al. Pulmonary hypertension and cor pulmonale during severe acute chest syndrome in sickle cell disease. Am J Respir Crit Care Med 2008; 177:646-653.

44. Mathai SC, Hummers LK, Champion HC, Wigley FM, Zaiman A, Hassoun PM, Girgis RE. Survival in pulmonary hypertension associated with the scleroderma spectrum of diseases: impact of interstitial lung disease. Arthritis Rheum 2009;60:569-577.

45. Murali S, Kormos RL, Uretsky BF, Schechter D, Reddy PS, Denys BG, Armitage JM, Hardesty RL, Griffith BP. Preoperative pulmonary hemodynamics and early mortality after orthotopic cardiac transplantation: the Pittsburgh experience. Am Heart J 1993;126:896-904.

46. Krowka MJ, Plevak DJ, Findlay JY, Rosen CB, Wiesner RH, Krom RA. Pulmonary hemodynamics and perioperative cardiopulmonary-related mortality in patients with portopulmonary hypertension undergoing liver transplantation. Liver Transpl 2000;6:443-450.

47. Taylor JG VI, Nolan VG, Mendelsohn L, Kato GJ, Gladwin MT, Steinberg MH. Chronic hyper-hemolysis in sickle cell anemia: association of vascular complications and mortality with less frequent vasoocclusive pain. PLoS ONE 2008;3:e2095.
48. Kato GJ, McGowan V, Machado RF, Little JA, Taylor J VI, Morris CR, Nichols JS, Wang X, Poljakovic M, Morris SM, Jr., Gladwin MT. Lactate dehydrogenase as a biomarker of hemolysis-associated nitric oxide resistance, priapism, leg ulceration, pulmonary hypertension, and death in patients with sickle cell disease. Blood 2006;107:22792285.

49. Kato GJ, Onyekwere OC, Gladwin MT. Pulmonary hypertension in sickle cell disease: relevance to children. Pediatr Hematol Oncol 2007; 24:159-170.

50. Gordeuk VR, Sachdev V, Taylor JG, Gladwin MT, Kato G, Castro OL. Relative systemic hypertension in patients with sickle cell disease is associated with risk of pulmonary hypertension and renal insufficiency. Am J Hematol 2008;83:15-18.

51. Reiter CD, Wang X, Tanus-Santos JE, Hogg N, Cannon RO III, Schechter AN, Gladwin MT. Cell-free hemoglobin limits nitric oxide bioavailability in sickle-cell disease. Nat Med 2002;8:1383-1389.

52. Takeda Y, Tomimoto S, Tani T, Narita H, Kimura G. Bilirubin as a prognostic marker in patients with pulmonary arterial hypertension. BMC Pulm Med 2010;10:22. 